\title{
May the Change Be with You: The Need for New Roles to Support Flipped Classroom Development
}

\author{
Linda Blömer $^{(\bowtie)}$, Alena Droit ${ }^{(\bowtie)}$, and Kristin Vogelsang ${ }^{(凶)}$ \\ Osnabrueck University, Katharinenstr. 3, 49074 Osnabrueck, Germany \\ \{linda. bloemer, alena. droit, \\ kristin.vogelsang\}@uni-osnabrueck.de
}

\begin{abstract}
The usage of digital media to provide learning content is becoming increasingly popular. One form of e-learning is the Flipped Classroom (FC). FC courses, however, are still heavily dependent on the commitment of individual teachers. Repeatable descriptions of approaches or institutionalized support are rare. The high amount of work involved discourages many teachers from using FCs. Strategic course development should therefore be conducted collaboratively by several stakeholders. Change management approaches offer a solution to deal with the integration of strategies for change and consider all stakeholder groups. This paper aims to combine an FC process model and a change management approach to include all stakeholders. Based on a literature review, we develop an integrative approach and summarize the necessary aspects of change. Our results show that for the successful integration and development of FC courses, we need new roles that support the process and assure the stakeholder's acceptance.
\end{abstract}

Keywords: Flipped Classroom $\cdot$ Change management $\cdot$ Stakeholder $\cdot$ Course development $\cdot$ Literature review

\section{Introduction}

The practice of teaching has undergone fundamental changes. The integration of technology for the supply of content and learning material leads to improved e-learning variants [1]. One method of so-called blended learning (BL) is the Flipped Classroom (FC). In an FC, the essential basic knowledge is supplied via online material and can be learned at home, while the in-class time can be used to train deeper understanding and application of the knowledge [2]. As the concept is rather new, much research only deals with siloed - and therefore, often heterogeneous case presentations [3]. Process models that present the development process are rare $[4,5]$. Often, the FC is planned and proceeded single-handedly by the teachers. Supportive institutional structures are hardly ever available. The transformation of a traditional course is a time-consuming task [6] in which the teacher should be supported by a clear division of roles and tasks. The high amount of work involved discourages many teachers from using technologyenhanced approaches for teaching [7]. The role of the institution and its supporting duties are not defined [8]. Newly created FC design models fall too short, as they 
assume a high intrinsic motivation of all stakeholders. However, research has already proven a resistance to change among students, teachers, and administration [9]. Change management (CM) that accompanies stakeholders and directs the change is often missing [10]. Due to the defined lack of applicable process models that include stakeholders and motivational structure, this paper links an FC process model with a $\mathrm{CM}$ approach. The aim is to present the possible connections between FC development and CM integration. Doing so, we will answer the following three research questions (RQ): (1) Which CM approaches are considered in the current FC literature? (2) What tasks and recommendations to change, referred to as CM aspects, can be identified and linked to the FC development process? (3) What other CM aspects should be taken into account in a stakeholder-integrating FC development process in the future?

Based on a literature review, we decide to link a CM model with an FC process model to disclose similarities between the FC development and the change process. We define how a successful CM can support the FC development process and foster the distribution of the tasks arising. Also, we emphasize which aspects cannot be directly assigned to the development process, but should nevertheless be considered in the sense of a successful change process. To achieve this, we have conducted a research process based on a systematic literature review described in Sect. 2. In Sect. 3, we will present the theoretical basis: The selected FC process model [11] as well as the underlying CM model from Kotter [12]. We then link the CM aspects derived from the literature review with both models in Sect. 4 and discuss supplementary aspects without direct reference to the FC development process in Sect. 5. Further research and limitations of our work are also covered in the section. The paper ends with a conclusion in Sect. 6. We regard the paper as a wake-up call for higher education institutions (HEI) to recognize the importance of a fundamental and managed change, involving all stakeholders, providing support and structure, and breaking down barriers.

\section{Method}

Our research process shown in Fig. 1 is based on a literature review [13] that leads to a merge of two different models.

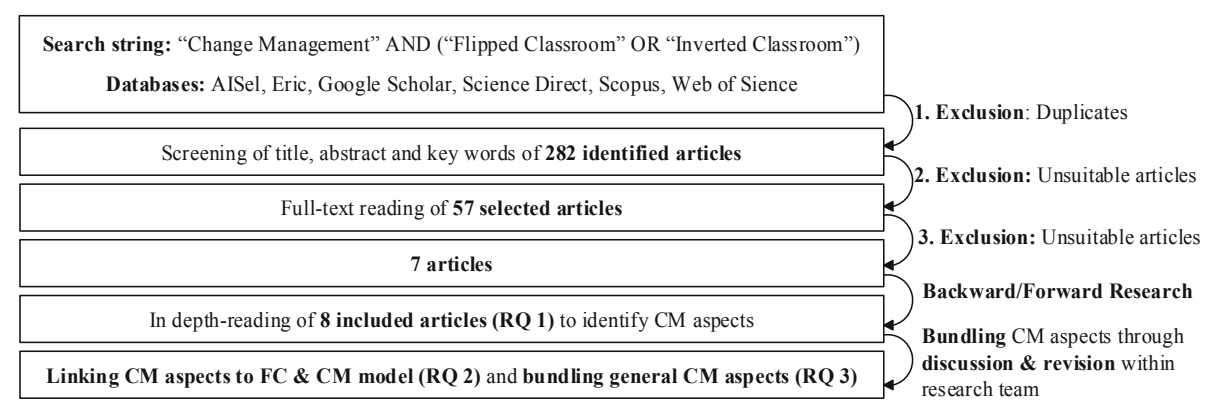

Fig. 1. Research process 
The aim is to identify current articles and conference proceedings that deal with the consideration of CM during the development of an FC course and show which CM approaches have been applied (RQ 1) to identify $\mathrm{CM}$ aspects, that can be linked to specific checklist tasks (CTs) of the FC process model as well as to steps of the CM model (RQ 2) or be bundled to general CM aspects (RQ 3). We searched in six databases using the search string and limiting the results from 2015 to get only current sources. After deducting duplicates in the first exclusion, we identified 282 articles of which title, abstract, and keywords were screened for relevance. Reasons for the second exclusion were a lack of relevance to $\mathrm{CM}$ and FC or at least BL and a lack of quality when the source was not published as a journal or conference paper. We selected 57 articles for full-text reading rejecting 50 of them during the third exclusion which we carried out taking into account the criterion lack of relevance to CM and FC/BL, lack of relevance for HEI as well as lack of application of a CM approach. Afterward, we conducted a backward/forward research determining one more article as relevant for our study. Our findings are summarized in Table 1, in which the CM approach, the mainly addressed stakeholder (Ad. ST) and the primary goals of the paper are noticed.

Table 1. Considered CM approaches in current FC literature

\begin{tabular}{l|l|l|l}
\hline Author [Ref.] & CM approach & Ad. ST & Major goal \\
\hline Berglund et al. [14] & Self-developed & Institution & $\begin{array}{l}\text { Establishment of the role } \\
\text { "pedagogical developer" to } \\
\text { accompany the CM }\end{array}$ \\
\hline Daniel et al. [15] & Self-developed & Teacher & $\begin{array}{l}\text { Overcome challenges for teachers by } \\
\text { training students as multipliers for } \\
\text { digital learning }\end{array}$ \\
\hline $\begin{array}{l}\text { Collyer and } \\
\text { Campbell [16] }\end{array}$ & $\begin{array}{l}\text { CM model } \\
\text { (Kotter) }\end{array}$ & Institution & $\begin{array}{l}\text { Build a grounded theory for adequate } \\
\text { technology adoption change support }\end{array}$ \\
\hline Hurtubise et al. [17] & $\begin{array}{l}\text { CM model } \\
\text { (Kotter) }\end{array}$ & Teacher & $\begin{array}{l}\text { Build a pedagogical strategy for FC } \\
\text { implementation using CM methods }\end{array}$ \\
\hline $\begin{array}{l}\text { Hutchings and } \\
\text { Quinney [10] }\end{array}$ & $\begin{array}{l}\text { Triple helix model } \\
\text { of change } \\
\text { (Hutchings et al.) }\end{array}$ & Institution & $\begin{array}{l}\text { Transform the learning experience } \\
\text { and organizational culture to adopt } \\
\text { technology-enabled learning }\end{array}$ \\
\hline Quinn et al. [18] & $\begin{array}{l}\text { CM model } \\
\text { (Kotter) }\end{array}$ & Institution & $\begin{array}{l}\text { Using CM principles to engaging } \\
\text { students into the learning culture in } \\
\text { e-learning }\end{array}$ \\
\hline $\begin{array}{l}\text { Van Twembeke } \\
\text { and Goeman [19] }\end{array}$ & Self-developed & Institution & $\begin{array}{l}\text { Examination of what leads adult } \\
\text { education teachers to integrate FC and } \\
\text { seeks to cultivate CM principles }\end{array}$ \\
\hline White et al. [20] & Self-developed & Staff/teacher & $\begin{array}{l}\text { Development of strategies to foster } \\
\text { transformational change in teaching } \\
\text { and learning using a range of active } \\
\text { learning strategies }\end{array}$ \\
\hline
\end{tabular}


The results of the literature review show that there are only a few articles taking into account a CM approach while developing a BL method like FC. This also corresponds to the results of other researchers for FC [17] and blended learning [18, 21]. In three of the eight articles, the well-known CM approach of Kotter was chosen. Most of the articles shown in Table 1 address the institution as a whole or at least teachers and further staff. We assume that an institutional anchoring and a distribution of tasks to clearly defined roles within the institution is needed. To identify such tasks, as well as recommendations to change, that should be considered in the FC development process, we continue to proceed our research as follows in this paper: First, we describe the $\mathrm{FC}$ creation process on the one hand and the $\mathrm{CM}$ process on the other hand. Therefore, we merge the FC process model [11] and Kotter's CM model [12], as Kotter's approach is the only one that is used in several included articles. The chosen models build the basis for assigning $\mathrm{CM}$ aspects derived out of the eight papers from the underlying literature review. To do so, we screened the articles for relevant CM aspects. We collected a total of $79 \mathrm{CM}$ aspects, discussed the content within our team of three experienced FC researchers and assigned the aspects to the CTs of the FC process model as well as the steps of Kotter's CM model whenever possible. Doing so, we could link $46 \mathrm{CM}$ aspects with both models (Sect. 4). $33 \mathrm{CM}$ aspects could not be assigned to single CTs of the FC process. They were as well discussed within the team and clustered (Sect. 5).

\section{Theoretical Basis}

An FC is defined as a concept in which interactive, group-based learning activities take place in the classroom, while individual learning occurs outside the classroom [2]. Many studies prove the success of FC concepts [9]. Videos, podcasts, and reading assignments provide basic knowledge, which is studied individually by the students online [22]. The attendance time of the FC is arranged differently according to the needs; the main focus is on the application of the knowledge imparted online, problemoriented and collaborative learning as well as discussions between the students and the teacher [23]. The implementation of the FC courses is heterogeneous and scientific findings, therefore, challenging to transfer. Many researchers and users in this field wish for uniform procedure models for the creation of FC courses [24]. First models for FC design came up, which primarily concentrate on content creation [4] and student learning [25].

Table 2. FC process model checklist [11]

\begin{tabular}{l|l|l}
\hline Phase & No. & Checklist task \\
\hline Initiation & 1 & Define need and goals \\
\cline { 2 - 3 } & 2 & Estimate time, staff, and financial expenses \\
\cline { 2 - 3 } & 3 & Identify stakeholders (lecturers, students, institution) \\
\cline { 2 - 3 } & 4 & Weigh benefits and costs and make a decision whether FC is useful \\
\hline
\end{tabular}

(continued) 
Table 2. (continued)

\begin{tabular}{l|l|l}
\hline Phase & No. & Checklist task \\
\hline Planning & 5 & Activate project team \\
\cline { 2 - 3 } & 6 & Train teachers \\
\cline { 2 - 3 } & 7 & Check if changes/plans are in accordance with university requirements \\
\cline { 2 - 3 } & 8 & Define learning outcomes and levels with the help of taxonomies \\
\cline { 2 - 3 } & 9 & Identify group of learners (context, diversity) \\
\cline { 2 - 3 } & 10 & Inform students in advance \\
\cline { 2 - 3 } & 11 & Prepare and produce material (choose media type) \\
\cline { 2 - 3 } & 12 & Choose in-class activities and prepare material \\
\cline { 2 - 3 } & 13 & Tune in-class and online courses \\
\cline { 2 - 3 } & 14 & Prepare learning analytics \\
\cline { 2 - 3 } & 15 & Check and provide resources (rooms, technical equipment, LMS) \\
\hline Execution & 16 & Provide online material \\
\cline { 2 - 3 } & 17 & Continuous learning assessment \\
\cline { 2 - 3 } & 18 & Proceed in-class activities \\
\cline { 2 - 3 } & 19 & Monitor participants and learning success \\
\cline { 2 - 3 } & 20 & Steer according to students needs \\
\hline Closing & 21 & Cany out exams \\
\cline { 2 - 3 } & 22 & Conduct formative evaluation (attitudes, perceptions) of stakeholders \\
\hline & 23 & Conduct summative evaluation (learning success) of students \\
\hline & 24 & Lessons learned \\
\hline
\end{tabular}

For the instructional design of an FC that integrates CM, we chose an already existing FC process model [11]. As the FC process model has its roots in project management, we assume that further stakeholder can easily be included. Four successive project management phases initiation, planning, execution, and closing [26] describe the process and the activities of FC development. A supplementary checklist with CTs for each phase is shown in Table 2. During the initiation phase, the idea of the project comes up and has to be evaluated. Risks and impacts are considered for preparing the decision about the project execution. In the second phase, the planning, required resources are identified and plans for time, costs, and performance are developed. The third phase is often presented in two sections (testing and execution). Here the FC takes place. The closing phase includes an evaluation of the project and its output. Lessons learned are collected. Besides the practical implications of this model, we assume, the model profits from some enhancements to include stakeholder and their tasks from a broader perspective than the core teaching team.

The results of our literature research show that Kotter's eight-step process is the only established CM approach described in multiple articles. John P. Kotter's work is based on the experiences he made during the observation of several companies, which were dealing with the process of change. According to Kotter, mistakes can have a destructive effect on the whole change process. In his work, he focuses on eight errors, from which he derives the eight steps to transform an organization [12]. Figure 2 gives an overview of the steps. 


\begin{tabular}{|c|c|c|c|c|c|c|c|}
\hline Step 1 & $\square$ Step 2 & Step 3 & Step 4 & Step 5 & Step 6 & Step 7 & Step 8 \\
\hline $\begin{array}{l}\text { Establishing a } \\
\text { Sense } \\
\text { of Urgency }\end{array}$ & $\begin{array}{l}\text { Forming a } \\
\text { Powerful Guiding } \\
\text { Coalition }\end{array}$ & Creating a Vision & $\begin{array}{l}\text { Communicating } \\
\text { the Vision }\end{array}$ & $\begin{array}{l}\text { Empowering } \\
\text { Others to Act on } \\
\text { the Vision }\end{array}$ & $\begin{array}{l}\text { Planning for and } \\
\text { Creating } \\
\text { Short-Term Wins }\end{array}$ & $\begin{array}{l}\text { Consolidating } \\
\text { Improvements and } \\
\text { Producing Still } \\
\text { More Change }\end{array}$ & $\begin{array}{l}\text { Institutionalizing } \\
\text { New Approaches }\end{array}$ \\
\hline
\end{tabular}

Fig. 2. Kotter's CM model [12]

Step 1 is based on current facts, communicated tactically to stimulate the formation of motivated collaborations. At the beginning of the change process, the acceptance to change from at least three-quarters of the management is critical to success for the whole change process. Excellent leaders with comprehension for the necessity of change are required. Step 2 underlines the importance of guiding coalitions, which rely on power. Numerous influential individuals are needed, breaking loose with former hierarchy structure and earlier formalities within their cooperation, working as a team a steep challenge when they, until then, were used to reach goals on their own and therefore overlook the significance of such a coalition. Step 3 assumes responsibility to sketch and maintain the direction of change, defining a vision that is simple to communicate and easy to understand in a short time, inducing comprehension and interest and combining all single plans to a future perspective. The vision has to be spread through every communication channel, as step 4 demands. The change will fail without the support of many people, based on their trust in the change, willing to make concessions at their expense. Therefore, extensive and believable communication is indispensable, even if still not enough. Step 5 makes clear that in the following process, serious barriers to change have to be determined and removed so that people are enabled to adjust their organization on the vision. Step 6 deals with the relevance of diverse goals, that can be reached and celebrated in short steps during the change process. This short term wins have to be planned and created, e.g., to prevent people discontinuing or even start rejecting the change. However, once proclaiming a concluding triumph is dangerous, step 7 considers. In this process step, it is more advisable to go on with short term wins in broader contexts, taking care of organization parts that did not change yet, be aware of prospective recruiting and development and start new, more extensive projects. Step 8 anchors the change within the culture by communicating relevant circumstances that enabled the positive change and the resulting success and by anchoring the new approaches within the next generation [12].

We share Kotter's opinion that a vision of the change process can reduce the error rate [12]. Therefore, we link CM to an FC development to not just reflect the creation process, but also the process of change.

\section{Consideration of CM During FC Development}

We identified $46 \mathrm{CM}$ aspects of which we were able to assign each of them to a single checklist task (CT) of the FC process model and to a step of the CM model by searching for parallels. This approach should be seen as a superior supplement to mere course development models. The focus here is not on imparting knowledge, but on the long-term integration of the FC course system, supported by institutional anchoring. 
Table 3 illustrates the distribution of $\mathrm{CM}$ aspects and the connection between the two models. While $10 \mathrm{CM}$ aspects could be linked to the initiation phase, 25 to the planning phase and 11 to the closing phase of the FC process, no CM aspect could be assigned to the execution phase. The phases of the FC process and assigned CM aspects are explained below.

Table 3. Linking CM aspects with FC and CM model

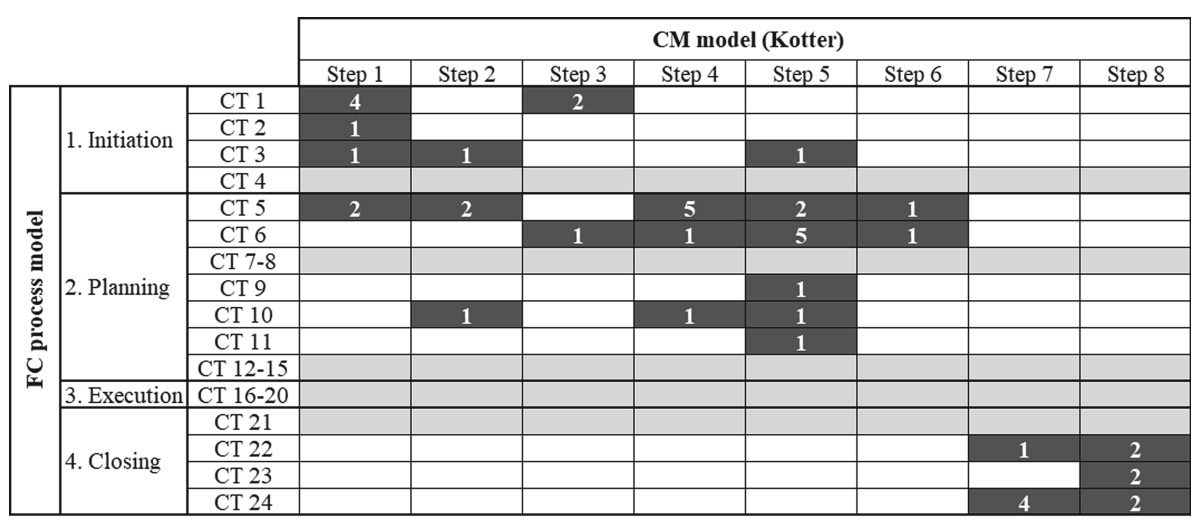

1-5 Number of CM aspects linked with a particular CT of the FC model and a step of the CM model CT without linking to $\mathrm{CM}$ aspects

\subsection{Initiation Phase}

The first phase of the process model is the initiation phase, which starts as soon as a teacher considers to introduce an FC by converting an existing course or creating a new course. The phase includes all process steps from the first idea to the decision for or against the FC and the communication of the vision of the FC class (CT 1-4). Implementing CM is particularly crucial at the beginning of the FC development; Most of the CTs are closely linked to one or more steps of Kotter's CM model. At the very beginning, goals and needs for an FC (CT 1) have to be defined, which corresponds directly with the task to generate necessity for digital transformation in classrooms (step 1). The initiators should explain and justify the change [14] to all affected stakeholders at an early stage. Existing problems in teaching should be discussed in retrospect, and the need didactical change should be demonstrated $[18,20]$. It is important to create awareness for the usefulness of the learning system, including the voices of industry leaders [16]. By creation an induction experience that allowed students to self-assess their needs and undertake development as required before the beginning of a course, teachers can motivate students for the FC [18]. The estimation of time, staff and expenses (CT 2) can be linked to Kotter's first step as well. From a CM perspective (step 1), Berglund et al. [14] recommend the establishment of pedagogical developers (PDs); Highly motivated teachers who work part-time as PDs to promote pedagogical development and facilitate cooperation and knowledge exchange among 
faculty members at the HEI [18]. The identification of all affected stakeholders (CT 3) can be linked to the first, second and fifth CM step. The FC initiators should demonstrate the benefits of FC teaching clearly and ensure teachers that support and training will be available for them and all other affected stakeholders (step 1) [16]. It is crucial to involve the relevant stakeholders for the FC transformation from an early stage. A guiding coalition should be formed, including not only teachers, students and administration but also technical support, faculty development leader and curricula designers (step 2) [17]. When involving the stakeholders, their diversity must be considered: Van Twembeke et al. found out, that teachers often feel frustrated when basic accomplishments were overlooked and not valued, especially because skills that seem self-evident for younger teachers might be hard to master for older or less digital literate teachers (step 5) [19].

\subsection{Planning Phase}

The planning phase includes all the tasks to organize the FC in general and in detail, involving the affected stakeholders in each stage (CT 5-15). Concerning the CTs, this phase is the most extensive. First, the project team must be activated (CT 5). Together they agree on an action plan, that can be subsequently adapted into a project management document, as a BL agreement (step 1) [18]. To connect a powerful stakeholder coalition (step 2) interdisciplinary networking should be promoted within and outside of the institution $[10,19]$ and connections should be formed between lecturers to share and extend knowledge and best practices $[19,20]$. It can help to organize workshops to create and inform the stakeholders about the FC vision [18] (step 4). Also, peer-to-peer interaction is useful [19]. Peer assessment activities through platforms and peerreflection about teaching and learning concepts and implementations between teachers have been proven beneficial for the change process [18] (step 4). To transplant the vision of the FC approach (step 5), regular meetings of involved stakeholders should be held at the institution [19] to exchange ideas, feedback, and knowledge. Furthermore, White et al. motivate stakeholders to overcome barriers (step 5) by constantly communicating "why" and "how" FCs should be implemented and point out the advantages and possible applications of FC methods [20]. To support teachers while planning and executing the FC (step 6), the institution can provide shared workspaces, where teachers can prepare new materials and have access to books and materials supporting technology-enhanced teaching [19].

The training of teachers plays an essential part during the CM process (CT 6). To assure the use of the systems, teachers, and students must have unrestricted access to the system (step 3). It implies that teachers, in particular, should be able to use the system in terms of content and technology [10]. Also shared vision and agreement on how the technical system will be used in teaching is needed (step 4). Therefore, the expected effort must be realistically estimated and communicated [19]. Specifically, the support and training opportunities for teachers should be developed and offered [14]. Training that focuses on teaching in the digital environment is particularly important [15]. The combination of technical and didactical training is a distinctive feature of FC [19]. These measures are necessary to remove potential barriers in advance (step 5). This also includes providing comprehensible materials, for example, in the first 
language [19], so that the necessary steps for electronic teaching are easy to understand [19]. To rely on existing, functioning technical tools and start learning the basics [15], can be an easy way to gather short-term wins (step 6).

To check if changes and plans are in accordance with university requirements (step 7) and to define learning outcomes and levels with the help of taxonomies are subsequent significant actions. These tasks refer to the instructional design of the FC. The underlying CM literature suggests no further actions taken focusing these stages due to the strong relation to the didactical part of the FC. When the learning goals are settled, the teacher should spend some time to classify the group of learners taking the content and the different preconditions (CT 9) into account. The consideration of the diversity of the students is a key to enable the overcoming of potential barriers (step 6) [19]. Now the focus is on involving the students. They should be informed in advance about the course and the requirements (CT 10). This also includes explaining the benefits of the course. In concrete terms, former students or practitioners can advertise and explain the benefits of the classes for their future careers [18]. The course can be advertised with these strong stakeholder alliances (step 2). Students are informed comprehensively through different channels [17] (step 4) and the information about the course is provided [18]. This step also serves to overcome potential barriers (step 5). Once the learning material has been created, and the corresponding media type has been selected (CT 11), the material can be made available to the students [18]. Here it is crucial to identify and remove potential barriers that make access to the material more complicated, such as technical barriers or language barriers (step 5).

The final CTs of the planning phase are again strongly focused on the interaction of the teachers with the students. Once the students' diversity is defined in advance, inclass activities can be selected, and the material prepared (CT 12). The current in-class activities will now be tuned to the online courses (CT 13). The preparation of the Learning Analytics (CT 14) is also based on the previous steps towards CM. The information used in step 7 is used here. This phase concludes with a final check of resources. Rooms must be booked, and the technical equipment should be available and accessible. The same applies to the learning management system (LMS) (CT 15).

\subsection{Execution Phase}

The execution phase is the most challenging part of FC development. Here most actions are taken that focus on the proceeding of the courses. It, therefore, seems somewhat surprising that we were unable to work out clear recommendations for action on $\mathrm{CM}$ from the selected literature. We see the reason for this in the fact that many CM measures have already been established at this point. Help structures regarding administrative activities and technical support should already be anchored. Stakeholders should already be informed at this point and follow a shared vision. New impulses from CM do not come to bear at this point. Instead, the team is now concentrating on the successful handling of the FC course. This includes above all the processing of CT 16-20: The online material is made available via existing systems. This is accompanied by opportunities for the students to continuously check their performance. The in-class activities take place at the same time. The teacher focuses on the participants and their learning success and steers his course according to the student's expectations and needs. 


\subsection{Closing Phase}

The final phase of the FC development and implementation is the closing phase. This phase marks the end of the FC process. The teacher and the teaching team must choose an evaluation method (step 8) and decide whether formative (CT 21) or summative (CT 22) methods or a combination of both are appropriate. There is a need for the adaptation of evaluation and assessment methods [17] to the course settings. The collection, comparison, and dissemination of research results [17] (step 8) is proper preparation of the lessons learned (CT 23) from the past course. In forums, teachers can discuss recent events retrospectively [14]. For this purpose, however, a suitable framework for these meetings must be created. Within established sessions, teachers can share their experiences [19] and knowledge [15]. Networking should be enabled [18]. Also, the derived success factors are communicated to the stakeholders (step 7).

To raise the interests of future students, the opportunities that arise through the courses should be promoted. The arising advantages should be reported through appropriate channels [18]. The FC approach can then be expanded to other courses and programs within the universities (step 7). This means this phase is, on the one hand, the closing of the current course but also the first preparation for future courses.

\section{Discussion}

Besides those CM aspects that could be linked to the FC process, we found a total of 33 aspects which are more general and therefore cannot be clearly assigned to a single CT. Instead, they are ongoing tasks and recommendations that should accompany the whole development process of FC thus concentrate on the management of the stakeholders. We defined the following five categories for accompanying CM aspects that should be taken into account in a stakeholder-integrating FC development process: (1) Care for the stakeholders: Make circumstances for stakeholders as pleasant as possible [16], show appreciation [19], remove barriers like insufficient time and money [19] and compensate the additional burden of time on teachers through the use of trained students [15] or the support of Ph.D. students [20] during all phases; and also note the changes in the requirements of stakeholders during the various phases. (2) Encourage teams: Create a sense of community [14] and promote the presence of the guiding coalition [19]. (3) Live the vision: Create and use a vision [20] that gets a proper name and is distributed across different communication channels [18]. Consider an FC establishment from bottom-up [19], set and communicate goals [20], use motivational techniques [18] and activate committed stakeholders [10]. (4) Offer permanent support: Form a team for support [18] and provide necessary framework conditions [10]. Offer emotional support and encourage self-confidence of teaching staff [19]. Concentrate on established technological tools [16] and support voluntary participation of teachers [15]. (5) Enable step-by-step procedure: Implement FC step-by-step [20] by starting small, flipping one lecture at a time, executing pilots and preparing subareas [17]. Set intermediate goals [19], evaluate the progress [16] communicate the first results [18], and employ feedback loops [16]. Enable reflection [18] and promote presentations of cases and pilots [16]. 
In literature, it often remains unclear who exactly will take on the task to guide the change. As shown in Table 1, either the institution is addressed in general terms or tasks are assigned to the teacher. Thus, we call for new roles in HEIs, which overtake the task to guide the change and take into account the individual FC phases as well as the consideration of the entire CM process. Such a position could be located within the organizational development of HEI, initiate the change together, accompany stakeholders, and thus act as a present and responsive support.

\section{Conclusion}

By disclosing the relevant $\mathrm{CM}$ aspects for the change to digital teaching, we will show institutions how they can support relevant stakeholders in a targeted and holistic way during the change in the future. We combined two perspectives and merged them into one overview of how CM can be integrated to foster a successful FC development. Our literature research has shown that many authors have recognized the critical role of CM in the digital transformation of education.

Despite the merits of our model, we have to name some limitations. Although we based our research and the model development on well-prepared literature research, it is possible that models exist, that would be suitable as well.

The alignment of CM process steps and CTs to design an FC give hints for several stakeholders. Compared to the existing literature, we do not focus solely on the inclusion of the teachers and students in the FC implementation focus. We consider all different stakeholders. We assume the findings to be of value for teachers and teaching teams to implement new FC concepts or improve existing ones. The integration of $\mathrm{CM}$ to an FC process model is of particular relevance for researchers from the fields of elearning, instructional design, CM, and Process Management, especially in HEI. For further research we would welcome reports about FC development projects, that rely on our findings. Furthermore, stakeholder specific action plans should be developed and tested. In the long-term, it could be of value to see how the strategic stakeholderbased FC development affects the satisfaction of the recipients.

Furthermore, the role and tasks of the institution are still somewhat unclear [8]. It would be the aim of future research to clarify the promotional and driving role of the institutions and to define the implications of the change for the stakeholders involved [21]. We claim here for the creation of new supporting roles like a teaching coach and teaching teams that are responsible for successful CM in FC course implementation.

\section{References}

1. Güzer, B., Caner, H.: The past, present and future of blended learning: an in depth analysis of literature. In: Laborda, J., Ozdamli, F., Maasoglu, Y. (eds.) WCES 2013 (2013). Procedia - Social and Behavioral Sciences, vol. 116, pp. 4596-4603. Elsevier, Amsterdam (2014)

2. Bergmann, J., Sams, A.: Flip Your Classroom: Reach Every Student in Every Class Every Day. International Society for Technology in Education, Alexandria (2012) 
3. Lundin, M., Rensfeldt, A., Hillman, T., Lantz-Andersson, A., Peterson, L.: Higher education dominance and siloed knowledge: a systematic review of flipped classroom research. Int. J. Educ. Technol. High. Educ. 15(20), 1-30 (2018). https://doi.org/10.1186/s41239-0180101-6

4. Lee, J., Lim, C., Kim, H.: Development of an instructional design model for flipped learning in higher education. Educ. Technol. Res. Dev. 65(2), 427-453 (2017). https://doi.org/10. 1007/s11423-016-9502-1

5. Oeste, S., Lehmann, K., Janson, A., Leimeister, J.M.: Flipping the IS classroom-theorydriven design for large-scale lectures. In: 35th International Conference on Information Systems, Auckland, pp. 1-12. Association for Information Systems (2014)

6. Karabulut-Ilgu, A., Cherrez, N.J., Jahren, C.T.: A systematic review of research on the flipped learning method in engineering education. Br. J. Edu. Technol. 49(3), 398-411 (2018)

7. Gregory, M.S.-J., Lodge, J.M.: Academic workload: the silent barrier to the implementation of technology-enhanced learning strategies in higher education. Distance Educ. 36(2), 210$230(2015)$

8. Shnai, I.: Systematic review of challenges and gaps in flipped classroom implementation: toward future model enhancement. In: Mesquita, A., Peres, P. (eds.) ECEL 2017, Porto, vol. 16, pp. 484-490. Academic Conferences and Publishing International (2017)

9. Bishop, J.L., Verleger, M.A.: The flipped classroom: a survey of the research. In: 120th ASEE Conference and Exposition, Atlanta, GA, pp. 1-18 (2013)

10. Hutchings, M., Quinney, A.: The flipped classroom, disruptive pedagogies, enabling technologies and wicked problems: responding to 'the bomb in the basement'. Electron. J. eLearn. 13(2), 106-119 (2015)

11. Vogelsang, K., Droit, A., Liere-Netheler, K., Hoppe, U.: Designing a flipped classroom course - a process model. In: Ludwig, T., Pipek, V. (eds.) Proceedings of the Internationale Tagung Wirtschaftsinformatik (WI 2019), Siegen, vol. 14, pp. 345-359 (2019)

12. Kotter, J.P.: Leading change: why transformation efforts fail. Harv. Bus. Rev., 60-67 (1995)

13. Webster, J., Watson, R.T.: Analyzing the past to prepare for the future: writing a literature review. MIS Q. 26(2), xiii-xxiii (2002)

14. Berglund, A., et al.: The pedagogical developers initiative - systematic shifts, serendipities, and setbacks. In: Proceedings of the 13th International CDIO Conference, Calgary (2017)

15. Daniel, M., Hüther, J., Ohngemach, C.: Smile - Studierende als Multiplikatoren für innovative und digitale Lehre. In: Krömker, D., Schroeder, U. (eds.) DeLFI 2018, vol. 16, pp. 57-68. Gesellschaft für Informatik e.V., Bonn (2018)

16. Collyer, S., Campbell, C.: Enabling pervasive change: a higher education case study. In: Proceedings of EdMedia + Innovate Learning, Montreal, pp. 249-255. AACE (2015)

17. Hurtubise, L., Hall, E., Sheridan, L., Han, H.: The flipped classroom in medical education: engaging students to build competency. J. Med. Educ. Curric. Dev. 2, 35-43 (2015)

18. Quinn, D., et al.: Leading change: applying change management approaches to engage students in blended learning. Australas. J. Educ. Technol. 28(1), 16-19 (2012)

19. Van Twembeke, E., Goeman, K.: Motivation gets you going and habit gets you there. Educ. Res. 60(1), 62-79 (2018)

20. White, P.J., et al.: Adopting an active learning approach to teaching in a research-intensive higher education context transformed staff teaching attitudes and behaviours. High. Educ. Res. Dev. 35(3), 619-633 (2016)

21. Adekola, J., Dale, V.H.M., Gardiner, K.: Development of an institutional framework to guide transitions into enhanced blended learning in higher education. Res. Learn. Technol. 25 (2017). https://doi.org/10.25304/rlt.v25.1973 
22. Said, M.N.H.M., Zainal, R.: A review of impacts and challenges of flipped-mastery classroom. Adv. Sci. Lett. 23(8), 7763-7766 (2017)

23. McLean, S., Attardi, S.M., Faden, L., Goldszmidt, M.: Flipped classrooms and student learning: not just surface gains. Adv. Physiol. Educ. 40(1), 47-55 (2016)

24. Giannakos, M.N., Krogstie, J., Chrisochoides, N.: Reviewing the flipped classroom research: reflections for computer science education. In: Proceedings of the Computer Science Education Research Conference, pp. 23-29. ACM, New York (2014)

25. Chiang, F., Chen, C.: Modified flipped classroom instructional model in "learning sciences" course for graduate students. Asia Pac. Educ. Res. 26(1), 1-10 (2017)

26. Project Management Institute, P.M.: A guide to the project management body of knowledge: (PMBOK® guide). PMI, Newtown Square, Pa (2010) 